\title{
High Tie of the Inferior Mesenteric Artery in Curative Surgery for Left Colonic and Rectal Cancers: A Systematic Review
}

\author{
L.V. Titu E. Tweedle P.S. Rooney \\ Department of Surgery, Royal Liverpool and Broadgreen University Hospitals NHS Trust, Liverpool, UK
}

\section{Key Words}

Cancer, colon/rectum $\cdot$ Inferior mesenteric artery, high/low tie $\cdot$ Left colon, cancer $\cdot$ Rectum, cancer . Tie, inferior mesenteric artery disputable evidence of improved survival, the use of IMA high tie contributes to improved lymph node retrieval rates and accuracy of tumour staging.

Copyright @ 2008 S. Karger AG, Basel

\begin{abstract}
Background: During surgery for left colonic and rectal cancers, the inferior mesenteric artery (IMA) can be ligated either at its aortic origin (high tie) or below the origin of the left colic artery (low tie). There is no consensus as to which method should be employed. Methods: We searched Medline, EMBASE, Cochrane collaboration, and National Guidelines Clearinghouse databases and undertook a systematic review on the use of IMA high tie during curative resections for left colonic and rectal cancers and its impact on patient survival, peri-operative morbidity and mortality, and lymph node retrieval rates. Results: Sixteen studies were eligible for systematic review, including one randomized controlled study, 7 quasi-experimental studies, and 8 retrospective cohort studies. Data on 7,649 patients were analyzed, of whom 4,847 underwent high ligation of the IMA. Despite a trend for improved survival in patients in whom high tie was employed, there is no conclusive evidence to support this. Mortality and morbidity, including anastomotic leak and autonomic nerve injury rates, are similar, while lymph node retrieval is improved. Conclusions: Although there is no un-
\end{abstract}

\section{KARGER}

Fax +41613061234

E-Mail karger@karger.ch

www.karger.com
(C) 2008 S. Karger AG, Basel

$0253-4886 / 08 / 0252-0148 \$ 24.50 / 0$

Accessible online at:

www.karger.com/dsu

\section{Introduction}

Colorectal cancer is the second most common malignant tumour in the developed world, with age-adjusted rates of 26.6/100,000/year in females and 40.0/100,000/ year in males [1]. Left colonic and rectal cancers represent just under two thirds of all colorectal malignancies [2]. The mainstay of treatment is surgical, with removal of the tumour, adjacent bowel, and lymph nodes along its blood supply [3]. The presence or absence of lymph node metastases is the most important prognostic factor $[4,5]$.

The lymphatic drainage and route of metastatic spread for tumours of the rectum and left colon is along the main colic arteries to the aortic and inferior mesenteric groups of glands [6,7]; a significant proportion of draining lymph nodes are situated along the inferior mesenteric artery and vein. The extent to which removal of the proximal IMA-related lymph nodes is pursued varies greatly. Generally, the IMA is ligated either below the origin of the left colic artery (low ligation) or at its origin from the aorta (high ligation). If high ligation is employed, blood

Mr. Paul S. Rooney

Consultant Surgeon

Royal Liverpool and Broadgreen University Hospitals NHS Trust

Prescot Road, Liverpool L7 8XP (UK)

Tel. +44 1517063 426, Fax +44 1517065 828, E-Mail Paul.Rooney@rlbuht.nhs.uk 
supply to the distal colon is maintained through the marginal artery $[8,9]$.

Despite being advocated by Moynihan [10] in 1908, high ligation of the IMA remains controversial. Its acceptance has been hindered by a perceived lack of survival advantage combined with concerns about blood supply to the anastomosis and risk of injury to the hypogastric nerves [11]. Additionally, the wide dissection associated with this procedure requires advanced surgical skills and may prolong operating time. Conversely, it is conceivable that the use of a high tie provides a greater number of lymph nodes available for histopathological examination. This, in turn, could increase the accuracy of tumour staging, allowing more accurate prognosis predictions.

Based on these considerations, we set to identify, interpret, and discuss available evidence related to the use of IMA high tie in colorectal cancer surgery and identify directions for future research.

\section{Methods}

Search Strategy

We first searched the Cochrane Collaboration (www.cochrane.org/) database for systematic reviews on the level of the IMA ligation in left colonic and rectal cancers to ensure that a systematic review had not already been completed. The National Guidelines Clearinghouse (www.guideline.gov/) database was then searched using the terms '(colon or rectum) and cancer' to identify studies that specifically addressed the role of IMA high tie in curative surgery for colorectal cancer. Finally, the Medline (www.ncbi.nlm.nih.gov/entrez/) and EMBASE (www.embase. $\mathrm{com} /$ ) databases were searched using the following text words: 'inferior mesenteric artery'; 'lymph node' or 'lymph nodes'; 'colon' or 'rectum'; 'cancer', 'neoplasia', 'tumour', or 'tumor'. Additionally, references and citations from all retrieved articles were analyzed for identification of similar reports.

\section{Selection Criteria}

Two reviewers independently screened studies for inclusion. When duplicate or updated cohorts were identified, only the most recent study was included. When data for both colon and rectal cancers were included, separate data for left colonic and rectal cancers were sought.

Data Collection and Analysis

We reviewed all titles and obtained full-text copies of all potentially relevant studies. Each selected study was then analyzed for data on tumour location, survival, number of lymph nodes retrieved, proportions of Dukes' $\mathrm{C} 1$ (apical lymph node free from metastases) and C2 (apical node involved) tumours [12], and perioperative morbidity and mortality.

The primary outcome was the 5-year survival rate, and secondary outcomes were peri-operative mortality and morbidity and number of lymph nodes retrieved.

High Tie of the Inferior Mesenteric Artery

\section{Results}

No systematic reviews on the association between the level of IMA ligation and survival were found in the Cochrane Collaboration database. None of the 32 articles in the National Guidelines Clearinghouse database addressed the relationship between the level of IMA ligation and cancer survival. The Medline electronic database search yielded 37 citations; of these, 26 articles were discarded after an initial screen of the abstracts, leaving 11 papers that were retrieved and subjected to full-text and manual reference review. The EMBASE search retrieved 44 articles, 7 of which were already identified after the Medline search; of the remaining 37 papers, only 3 were retained for further analysis. Manual search of references from these 14 papers identified a further 2 articles included in the final study. In the end, there were 1 randomized controlled study, 7 quasi-experimental studies, and 8 retrospective cohort studies subjected to the systematic review.

\section{Randomized Controlled Studies}

There was only one prospective randomized trial, which compared survival and early morbidity and mortality rates between patients with left colonic cancer undergoing curative left hemicolectomy versus left segmental colectomy [13]. The lymph node at the origin of the IMA was removed in all patients, and was found to be involved by tumour in $2.6 \%$ of all cases and in $10 \%$ of Dukes' stage $\mathrm{C}$ patients. There were no significant differences in 12-year survival (47\% in left hemicolectomy vs. $54 \%$ in left segmental colectomy), anastomotic leak rates (11.5 vs. $14 \%$ ), overall morbidity (20.5 vs. $22.5 \%$ ), and 30 day mortality rates (6.1 vs. $2.3 \%$ ) between the two groups. Unfortunately, lymph node retrieval rates were not disclosed.

\section{Quasi-Experimental Design Studies}

The majority of these studies (table 1) date back to the 5th to 7th decades of the last century, when total mesorectal excision and multimodal treatments were not employed routinely. It is, therefore, conceivable that high local recurrence rates had a negative impact on any improvements in survival related to radical lymph node dissection.

In 1962, Rosi et al. [14] published their results on 291 patients who underwent curative resections for cancers of the left colon and rectum. Patients who underwent high ligation of the IMA had significantly higher overall 5 -year survival rates: 73.2 versus $66.4 \%(\mathrm{p}<0.05)$. This 
Table 1. Quasi-experimental design studies

\begin{tabular}{|c|c|c|c|c|c|c|c|c|c|}
\hline \multirow{2}{*}{$\begin{array}{l}\text { Authors } \\
\text { (year of } \\
\text { publication) }\end{array}$} & \multirow[t]{2}{*}{ Tumour location } & \multicolumn{2}{|c|}{ Patient numbers } & \multicolumn{2}{|c|}{ Mortality } & \multicolumn{2}{|c|}{ Morbidity } & \multicolumn{2}{|l|}{ 5-year survival } \\
\hline & & high tie & low tie & high tie & low tie & high tie & low tie & high tie & low tie \\
\hline $\begin{array}{l}\text { Rosi et al. [14] } \\
\text { (1962) }\end{array}$ & $\begin{array}{l}\text { rectum, descending } \\
\text { and sigmoid colon }\end{array}$ & 137 & 154 & $2.2 \%$ & $5.1 \%$ & NA & NA & $73.2 \%$ & $66.4 \%$ \\
\hline $\begin{array}{l}\text { Grinnell [15] } \\
(1965)\end{array}$ & $\begin{array}{l}\text { rectum, descending } \\
\text { and sigmoid colon }\end{array}$ & 179 & 181 & $6.2 \%$ & $5.5 \%$ & NA & NA & $5.7 \%$ higher (NS) & NA \\
\hline $\begin{array}{l}\text { Pezim and } \\
\text { Nicholls [17] } \\
(1984)\end{array}$ & rectum, rectosigmoid & 586 & 784 & $2.2 \%$ & $3.1 \%$ & $64 \%$ & $63.5 \%$ & $64.4 \%$ & $65.2 \%$ \\
\hline $\begin{array}{l}\text { Surtees et al. } \\
{[18](1990)}\end{array}$ & $\begin{array}{l}\text { Dukes' C stage } \\
\text { rectum, rectosigmoid }\end{array}$ & 150 & 100 & NA & NA & NA & NA & $64 \%$ for Dukes' C1 & $54 \%$ for Dukes' C1 \\
\hline $\begin{array}{l}\text { Slanetz and } \\
\text { Grimson [21] } \\
(1997)\end{array}$ & rectum, left colon & 1,107 & 1,154 & $4.2 \%$ & $5.0 \%$ & NA & NA & $\begin{array}{l}\text { 95\% Dukes' A colon } \\
\text { 88.2\% Dukes' A rectum } \\
\text { 84\% Dukes' B colon } \\
\text { 70\% Dukes' B rectum } \\
\text { 58.6\% Dukes' C1 colon } \\
\text { 39.9\% Dukes' C1 rectum } \\
\text { 26.9\% Dukes' C2 colon } \\
\text { 15.9\% Dukes' C2 rectum }\end{array}$ & $\begin{array}{l}\text { 95.3\% Dukes' A rectum } \\
\text { 87.9\% Dukes' A rectum } \\
\text { 76.6\% Dukes' B colon } \\
\text { 63\% Dukes' B rectum } \\
\text { 49\% Dukes' C1 colon } \\
\text { 37.7\% Dukes' C1 rectum } \\
\text { 26.2\% Dukes' C2 colon } \\
\text { 25\% Dukes' C2 rectum }\end{array}$ \\
\hline $\begin{array}{l}\text { Adachi et al. } \\
\text { [23] (1998) }\end{array}$ & $\begin{array}{l}\text { rectum, sigmoid } \\
\text { colon }\end{array}$ & 134 & 38 & 0 & 0 & NA & NA & $91.5 \%$ & $83.2 \%$ \\
\hline
\end{tabular}

NA = Not available; NS = not significant.

was felt to be due mainly to reduced local recurrence rates ( 2.9 vs. $18 \%, \mathrm{p}<0.01)$. Although the morbidity remained unchanged, the postoperative mortality rate dropped from $5.1 \%$ for segmental resection to $2.2 \%$ after hemicolectomy $(\mathrm{p}=0.1)$.

The most recent report from the Presbyterian Hospital in New York [15] compared the outcomes of 179 patients with cancer of the left colon and rectum, who underwent high ligation of the IMA, with those of a matching cohort of 181 patients who had low ligation. There were no differences in the peri-operative mortality rates (6.2 vs. $5.5 \%$ ), but no data are presented on the peri-operative complications. The 5-year survival for $151 \mathrm{pa}-$ tients with high IMA tie and 150 patients with low IMA tie for whom survival details were available indicated only a $5.7 \%$ advantage in favour of high ligation, which was not significant. When only Dukes' C tumours were considered, high ligation resulted in a 7.3\% higher survival rate. Lymph node metastases between the IMA origin and the origin of the left colic artery were found in 19 patients (10.9\%) of the high-tie group; of these, 17 developed residual disease. Similarly, the introduction of IMA high tie was not associated with a reduction in the pro- portion of Dukes' C2 tumours (11.8 vs. 13\%). The conclusion of this study is that, by the time the lymph nodes at the root of the IMA are involved by metastases, the disease has probably spread beyond the aortocaval nodes, and/or haematogenous metastases may have already occurred. This hypothesis is supported by more recent data [16].

Of particular interest is a paper from St. Mark's Hospital, London, which reported on the outcome of 1,370 patients who underwent curative surgery for rectal and rectosigmoid cancer [17]: $784(57.2 \%)$ cases had a low IMA tie and 586 patients (42.8\%) underwent a high IMA tie, with a $98.5 \% 5$-year follow-up rate. There were no significant differences between the two groups regarding 60 -day postoperative mortality (3.1\% for the high tie vs. $2.2 \%$ for the low tie) and complication rates (63.5 vs. $64 \%$ ). Although there were no differences in overall and agecorrected survival rates, patients with Dukes' stage C2 in the high-tie group fared significantly worse $(22.2 \mathrm{vs}$. $52.2 \%$ age-corrected 5 -year survival rate, $\mathrm{p}<0.05)$. One probable hypothesis, acknowledged by the authors in their discussion, would be that many of the Dukes' stage C2 patients in the low-tie group were in fact Dukes' stage 
C1, had a high tie been performed. A subsequent paper from the same institution [18] analyzed the survival of a selected cohort of 250 cases with Dukes' stage C rectal cancers, of whom 150 (53\%) underwent high IMA ligation. The number of harvested lymph nodes was higher in the high-tie group (median 17 vs. 13, mean 14.1 vs. 11.9). Five- and 10-year survival rates for Dukes' $\mathrm{C} 1$ cancers showed no significant difference between the two groups (64 vs. $54 \%$ at 5 years and 44 vs. $42 \%$ at 10 years in the high- and low-ligation groups, respectively). For Dukes' C2 tumours, although there was an apparently improved survival rate in patients treated by low IMA ligation, this was not significant. There were significantly $(\mathrm{p}=0.016)$ more patients with $>5-\mathrm{mm}$ extrarectal tumour invasion in the Dukes' C2 high-ligation group, which, the authors felt, was probably responsible for their poorer survival rates. An alternative explanation would be, however, that many of the Dukes' C2 cases in the lowligation group would have been in fact staged $\mathrm{Cl}$, had a high IMA ligation been performed, thus creating a stage migration phenomenon [19]. To minimize this effect, a subgroup of patients in the high-tie group with involvement of the 12th lymph node was compared to a Dukes' C2 tumour subgroup of patients in the low-tie group, with no significant survival differences observed. However, subgroup analysis is an unreliable statistical tool [20], and the results were likely to have been influenced by a significantly greater number of poorly differentiated tumours in the high-ligation group ( 73 vs. $17 \%, p<$ 0.001). Although the data presented did not demonstrate a survival benefit for high ligation of the IMA, the patient selection, sample size, and analytical methods used could easily have been inadequate for detecting small differences in survival, prompting the authors to advocate large, multicentre trials to address the question fully. To date, these have not materialized.

The records of 2,409 patients, who underwent curative resections for primary colorectal cancers at the Columbia-Presbyterian Hospital, New York, were analyzed according to the level of the IMA ligation: high in 1,107 cases and intermediate (effectively low, below the origin of the left colic) in 1,154 patients [21]. Postoperative mortality rates were comparable: $4.2 \%$ for high ligation and $5 \%$ for low ligation. Sufficient data were available to compare outcomes in 1,027 high ligations and 1,058 low ligations in patients with single primary colorectal cancers. The level of IMA ligation had no influence on the 5-year survival rates for patients with Dukes' stage A tumours, either colonic or rectal. Patients with Dukes' stage B colon cancers had significantly higher survival rates, if they underwent high IMA ligation (83.9 vs. $73.9 \%, \mathrm{p}<0.01$ ), but this effect was not seen in the rectal cancer subgroup. In patients with Dukes' C colorectal malignancies, a high IMA tie increased the overall 5year survival to $52.9 \%$, compared with $45.2 \%$ for those who had low ligation $(\mathrm{p}<0.05)$. No significant advantage to high IMA ligation was found in survival rates for Dukes' C1 or C2 rectal cancers and Dukes' C2 colon cancers, although patients with Dukes' $\mathrm{C} 1$ colon cancers faired better ( 58.6 vs. $49 \%$, p < 0.05). However, when five or more lymph nodes were involved, the level of ligation did not appear to influence survival rates. This confirms previous findings, which demonstrated that the positive effect of high IMA ligations is lost when the apical node is involved (Dukes' stage C2) and with increasing number of lymph nodes involved [15, 17, 22]. Nevertheless, in patients with intermediate lymph node involvement only, removing the uninvolved central lymph nodes by performing a high ligation of the IMA almost doubled the 5 -year survival rate (41.7 vs. $25.9 \%)$ and reduced the death rate from recurrent cancer from 66.7 to $38.9 \%$. Unfortunately, no data on postoperative morbidity were presented, although the authors [21] commented that this was not adversely affected by the high IMA high tie.

A more recent report on 172 patients with cancer of the rectum or sigmoid colon [23] found a low incidence of metastases involving the lymph nodes at the root of the IMA (less than 1\%) and concluded that the level of IMA ligation had no impact on the 5-year survival rate $(83.2$ vs. $91.5 \%$ for high and low ligation, respectively). There were no immediate postoperative deaths, and the incidence of postoperative complications was not different. Based on this, the authors declared that, for patients without serosal invasion or macroscopic lymph node involvement, removal of the pericolic and intermediate lymph node groups is sufficient. However, it is known that intraoperative judgement on the presence or absence of lymph node metastases is unreliable [24], questioning the validity of macroscopic lymph node involvement in the decision making on the extent of lymphatic resection.

Similar results were reported by another recent retrospective study on colonic cancers [25], although the number of lymph nodes harvested was significantly higher in the high-ligation group ( $23 \mathrm{vs.} 16, \mathrm{p}=0.0001)$. There were no details on peri-operative morbidity and mortality. Additionally, rectal cancers were specifically excluded, and the data presented did not allow breakdown of results for left-sided colonic malignancies. 
Table 2. Retrospective cohort studies

\begin{tabular}{|c|c|c|c|c|c|}
\hline $\begin{array}{l}\text { Authors } \\
\text { (year of publication) }\end{array}$ & $\begin{array}{l}\text { Number } \\
\text { of patients }\end{array}$ & Tumour location & 5-year survival rate & $\begin{array}{l}\text { Peri-operative } \\
\text { mortality }\end{array}$ & $\begin{array}{l}\text { Anastomotic } \\
\text { leak rate }\end{array}$ \\
\hline Bacon et al. [32] (1958) & 80 & $\begin{array}{l}\text { descending and } \\
\text { sigmoid colon, rectum }\end{array}$ & $60 \%$ & $3.1 \%$ & NA \\
\hline $\begin{array}{l}\text { Morgan and Griffiths [50] } \\
(1959)\end{array}$ & 214 & rectum, distal colon & NA & $1 \%$ & $1 \%$ \\
\hline Koyama et al. [33] (1984) & 495 & rectum & $62.2 \%$ & $1.4 \%$ & NA \\
\hline Leggeri et al. [35] (1994) & 252 & rectum & $\begin{array}{l}68.2 \% \text {, positive marginal nodes } \\
25 \% \text {, positive intermediate nodes } \\
30 \% \text {, positive central nodes }\end{array}$ & $5.1 \%$ & NA \\
\hline Cosimelli et al. [36] (1994) & 302 & rectum, sigmoid colon & $\begin{array}{l}58.5 \% \text {, rectal cancer } \\
65.7 \% \text {, sigmoid cancer }\end{array}$ & $4.3 \%$ & NA \\
\hline Hida et al. [39] (1998) & 198 & rectum & $\begin{array}{l}73.4 \% \text {, negative IMA origin nodes } \\
38.5 \% \text {, positive IMA origin nodes }\end{array}$ & NA & $6.3 \%$ \\
\hline Read et al. [45] (2002) & 131 & left colon & $84 \%$ & $1 \%$ & $1 \%$ \\
\hline Kanemitsu et al. [46] (2006) & 1,188 & $\begin{array}{l}\text { rectum and sigmoid } \\
\text { colon }\end{array}$ & $\begin{array}{l}50 \% \text {, positive intermediate nodes } \\
40 \% \text {, positive central nodes }\end{array}$ & $0.2 \%$ & $3.3 \%$ \\
\hline
\end{tabular}

\section{Retrospective Cohort Studies}

Many initial reports [26-30] describe technical aspects of radical lymph node dissection for cancers of the distal colon and rectum; however, the number of presented cases is small, and, although some data on mortality are available, there are no data on morbidity or survival. More recent reports (table 2) originate mostly from Japan, where a high tie of the IMA is widely used in combination with lateral pelvic lymph node excision.

McElwain et al. [31] examined the intramesenteric lymph nodes in specimens from 90 cases with cancer of the left colon, rectum, and anus in whom a high ligation of the IMA was performed. Lymph node metastases were found in 54 cases $(60 \%), 17.8 \%$ of which were located at the origin of the IMA. In 8 patients (9\%) a low IMA ligation would have left behind involved nodes, compromising the curative aspect of the operation. A larger study performed by Bacon et al. [32] reported on 416 patients with cancer of the left colon, rectum, and anal canal, who underwent high IMA ligation with a peri-operative mortality rate of 3.1\%. Lymph node metastases were present in 103 of 164 adenocarcinoma specimens available (62.8\%), with 18 (17.3\%) from patients having metastatic lymph node deposits at the IMA origin. Outcome data were traced in 80 patients, with a 5 -year survival rate of
$60 \%$, which compared favorably with that of $55 \%$ before the introduction of the high-tie approach. The 5-year survival rate for 11 patients with involved lymph node at the root of the IMA was $27.2 \%$. Although the survival rates are impressive, outcome data were reported in less than one quarter of the patients, raising the question of selection bias.

More positive results were reported by a large study from the National Cancer Center Hospital in Tokyo, Japan [33]. Extended lympadenectomy, including pelvic nodes for tumours located at or below the peritoneal reflection, was performed in 643 patients with rectal cancer, of whom 495 had a potentially curative resection. Overall, the 30 -day operative mortality was $2.2 \%$, with lower rates for curative operations (1.4\%); extended lympadenectomy did not increase the operative mortality. The overall 5-year survival rate for patients with curative resections was $62.2 \%$. For both Dukes' stage B and stage C, extended lympadenectomy was associated with significantly better 5 -year survival rates: 83.2 vs. $63.7 \%$ in Dukes' stage B cases and 52.5 vs. $30.8 \%$ in patients with Dukes' stage $C$ tumours $(p<0.01)$. This was mirrored by improved 5-year rates of overall cancer recurrence (15.4 vs. $37.9 \%$ in Dukes' stage B patients, $\mathrm{p}<0.02$, and 55.8 vs. $72.4 \%$ in Dukes' stage $C$ patients, $\mathrm{p}<0.01$ ) and local re- 
currence (8.4 vs. $26.1 \%$ in Dukes' stage B patients and 26.1 vs. $37.9 \%, \mathrm{p}<0.01$, in both groups). Nevertheless, local recurrence rates are high, raising questions about the quality of total mesorectal excision when compared to results reported by Cecil et al. [34]. All patients undergoing extended resections suffered from micturition problems, and all male patients were rendered impotent. Extended systematic lympadenectomy was also responsible for an average $60-\mathrm{min}$ increase in operating time; the average increase in blood loss was $150 \mathrm{ml}$.

Similar results were reported on 252 patients who underwent curative surgery for rectal cancer at the University of Trieste, Italy [35]. In all cases the IMA was ligated high, and all lumbo-aortic lymph nodes were cleared. The peri-operative mortality rate was $5.1 \%$. Although the anastomotic leak rate is not disclosed, this is one of the few studies providing functional outcome results. Erection and ejaculation were preserved in $76.1 \%$ of the patients who underwent sphincter-saving operations, in $62.5 \%$ of the cases treated with abdominoperineal resection, and in $50 \%$ of the patients in whom pelvic lympadenectomy was performed. Disorders of urinary function occurred in $4 \%$ of the patients with sphincter-saving operations, in $15.8 \%$ of the patients who had abdominoperineal resections, and in $20 \%$ of those who had lateral pelvic lymph node dissection. In Dukes' stage $\mathrm{C}$ patients, local recurrence was related to the site of the lymph node metastases: $17.7 \%$ in cases with marginal node involvement, $41.7 \%$ in those with intermediate lymph node involvement, and $50 \%$ in patients with central lymph node metastases $(\mathrm{p}=0.15)$. The overall 5 -year survival rates were $68.1 \%$ for patients with sphincter-saving surgery and $57.5 \%$ in those with abdominoperineal resections of the rectum. For Dukes' stage $\mathrm{C}$ tumours, the survival was clearly influenced by the level of proximal lymph node involvement: $68.2 \%$ in cases with marginal lymph node involvement, $25 \%$ in patients with intermediate lymph node metastases, and $30 \%$ in those with central lymph node metastases $(\mathrm{p}<0.0001)$. No metastatic deposits were found in the lateral pelvic wall nodes in the $16 \mathrm{pa}-$ tients who underwent extensive pelvic lymphadenectomy.

Another Italian study published in the same year [36] reported 5- and 10-year survival rates, urinary dysfunction, and sexual activity in 302 patients with cancers of the rectum and sigmoid colon who underwent lumboaortic lymphadenectomy, including IMA high tie. Of particular note is the high 5-year (42.7\%) and 10-year (42.7\%) survival for patients with Dukes' C2 tumours. In this study, total mesorectal excision was performed in rectal

High Tie of the Inferior Mesenteric Artery cancers, and systemic chemotherapy and/or high-dose pelvic radiotherapy were administered in selective Dukes' $\mathrm{B}$ and $\mathrm{C}$ patients, suggesting that modern multimodality oncologic therapy combined with nerve-sparing total mesorectal excision, as advocated by Heald [37], can achieve high survival rates even in Dukes' stage C2 tumours, contrary to previous reports $[15,17]$. Satisfactory sexual activity was maintained postoperatively in $46.5 \%$ of the males and in $47 \%$ of the females. Urinary dysfunction was infrequent: incontinence in $2.8 \%$ of males and $22.7 \%$ of females and retention in $4.2 \%$ of males and $1.5 \%$ of females. These results match those reported after total mesorectal excision with pelvic nerve preservation and low IMA tie [38], indicating that the level of IMA ligation has a minimal impact on sexual and bladder function, if precise anatomical plane dissection is employed.

In a retrospective analysis of 198 cases of rectal cancer, metastases at the root of the IMA were found in $8.6 \%$ of the patients [39]. None of the 46 patients with pT1 or pT2 tumours presented IMA root nodal metastases. The high mean number of lymph nodes examined per patient (73.5) was due to the use of the clearing method [40]. In the 144 patients who underwent a curative resection, the presence of metastases in the IMA root nodes was associated with a significantly lower 5 -year survival rate (38.5 vs. $73.4 \%$, $\mathrm{p}<0.05)$. The same group [41] obtained similar results in 164 patients with colon cancer, of whom 104 had left colonic tumours. There were no metastases identified in the central node for $\mathrm{pT} 1$ or $\mathrm{pT} 2$ cancers, with lower survival rates for patients with involved main nodes as compared with those where only the intermediate nodes were involved ( 30.0 vs. $48.7 \%, p<0.05)$. The absence of nodal metastases at the root of the IMA for early tumours was also confirmed by a report on 121 pT1 sigmoid cancers [42]. The problem with using pre-operative staging to guide the extent of lymph node dissection is the fact that, at present, no imaging technique offers absolute staging accuracy, particularly in identifying T1 tumours [43, 44]. The resultant risk is for a significant proportion of patients to undergo oncologically inadequate surgery.

Renewed interest in the level of the IMA ligation for left-sided colonic cancers was expressed by Read et al. [45], who observed a trend toward a poor prognosis for both locoregional control and disease-free survival, when the IMA was not divided at its aortic origin, but this did not reach statistical significance. Despite this, the high disease-free survival rate (84\%) achieved with $1 \%$ mortality and anastomotic leak rates encouraged the authors to recommend high IMA ligation and wide mesenteric resection as their preferred surgical technique. 
The most recent advocates of high ligation of the IMA in sigmoid colon or rectal cancer surgery are Kanemitsu et al. [46]. These authors prospectively collected data on 1,188 consecutive patients who underwent high ligation of the IMA for adenocarcinomas of the sigmoid colon or rectum. It was calculated that high IMA ligation increased the curative resection rate by $9 \%$, but only $0.7 \%$ of the patients were likely to be cured by this. Lymph node metastases at the root of the IMA were found in $1.7 \%$ of the patients who had an overall survival of $40 \%$ at 5 years and of $21 \%$ at 10 years, with cancer-specific survival of 42 and $23 \%$ at 5 and 10 years, respectively. This compares well with figures for patients with intermediate lymph node metastases: overall survival of $50 \%$ at 5 years and of $35 \%$ at 10 years and cancer-specific survival of $53 \%$ at 5 years and of $41 \%$ at 10 years. The postoperative mortality rate was very low $(0.2 \%)$, with a $3.3 \%$ anastomotic leak rate, a $31.5 \%$ overall morbidity rate, and a $29.2 \%$ surgical morbidity.

\section{Discussion}

The merits of different levels of IMA ligation must be judged with respect to their influence on survival, directly related peri-operative complications, and impact on staging and prognostic stratification.

Although it has been widely accepted that IMA high tie does not lead to improved cancer-related survival, most data originated from studies on operations performed 4-5 decades ago, when total mesorectal excision for rectal cancers and the use of adjuvant treatments in the form or chemo- and radiotherapy were not common practice. More recent reports have challenged this belief $[21,23,46]$. However, most of these studies originate in Japan, where IMA high tie is often combined with lateral pelvic lymphadenectomy, which makes interpretation of results difficult. The reported 40\% 5-year survival rate for patients with Dukes' C2 tumours has been replicated in two European series [35, 36], but whether this can be widely matched remains to be seen. While there is no unequivocal evidence of improved survival directly attributable to IMA high tie, in the majority of published studies patients who underwent this procedure had better survival rates $[15,17,21]$, but with one exception [15], the observed difference was not statistically significant.

Since any prospective study on the influence of IMA high tie on survival would have to recruit high numbers of patients and take several years to complete, an alternative would be to analyze locoregional recurrence patterns and to establish whether there is any relationship to the level of the IMA ligation. A study on regional mesenteric recurrence after anterior resection or left colectomy [47] established that, in $79 \%$ of the cases, IMA angiography demonstrated that the main arteries to the primary tumour had not been resected. In all patients with local recurrence, a high ligation of the IMA had not been performed, but the majority of cases also had residual superior rectal arteries.

There is now enough evidence to suggest that high tie of the IMA does not lead to increased peri-operative complications $[15,17,46]$ and/or mortality rates $[14,15$, $17,21,46]$. Despite the fact that approximately one fifth of the patients experience significant blood flow reduction after IMA clamping, ischaemia-related anastomotic complications are encountered in around 5\% of the cases, mostly elderly male patients [48]. Furthermore, a study comparing tissue oxygenation proximal to the colonic resection margin demonstrated that the marginal artery provides an adequate vascular supply to the transverse and descending colon [49], thus explaining the low anastomotic leak rates reported after high IMA ligation [39, $45,46,50]$. Although the superior hypogastric nerves are at risk, ligation of the IMA at its origin is the safest option in order to avoid damage to the autonomic nerves [51,52], which permits preservation of sexual and urinary functions in the great majority of the patients $[35,36,53]$.

The incidence of lymph node metastases along the IMA varies widely, and although initial studies reported higher rates [14, 15, 32], the majority of recent studies agree that metastatic deposits at the root of the IMA occur in less than $5 \%$ of the patients $[23,24,46,54,55]$. Central lymph node metastases are generally associated with deposits in other regional lymph nodes, but in up to $6 \%$ of the cases these might be the only involved nodes [31, 54]. It appears that involvement of central IMA nodes is the major determinant of disease-free survival, regardless of the status of the intermediate or paracolic nodes [54].

Although data on lymph node retrieval rates are scarce, it appears that ligating the IMA at its origin from the aorta significantly increases the number of lymph nodes harvested [25], considering that as many as 10 lymph nodes have been found along the segment of the IMA between the aorta and the origin of the left colic artery [15]. Indeed, this is supported by the fact that in all published series in which lymph node retrieval rates were disclosed, high IMA tie retrieved more that 12 lymph nodes [18, 24, $39,45,54,55]$, considered as being the minimum necessary for accurate tumour staging [3]. 
The most important aspect of lymph node staging is the presence or absence of apical node involvement [56, 57]. Patients with apical node metastases have 5 -year survival rates comparable to those presenting with distant metastases and are 2.5 times more likely to die from their tumour than patients with an uninvolved apical node [16]. This has recently been confirmed by Kim et al. [54], who found that metastases at the root of the IMA appear to be an independent prognostic factor.

To allow rigorous prognostic stratification, one must reduce the phenomenon of stage migration that might occur when comparing cohorts of patients who underwent high versus low ligation of the IMA. Indeed, a significant proportion of Dukes' C2 patients in the low-tie group would have been staged $\mathrm{C} 1$, had a high tie of the IMA been performed. It has been calculated that the routine use of high IMA ligation in suitable patients may result in the conversion of approximately 1 in 8 Dukes' C2 cases into Dukes' C1 cases [50].

The past two decades have seen an increasing popularity of the laparoscopic approach in the surgical treatment of colorectal pathology, including malignant disease. For left colonic and rectal lesions, high ligation of the inferior mesenteric vessels is often performed as a first operative step, facilitating the mobilization of the splenic flexure and laparoscopic dissection in the anatomical planes [58, 59]. The laparoscopic technique is associated with a low peri-operative mortality rate and lymph node retrieval, local recurrence, and overall survival rates that at least match those reported in open surgery [60-62]. More so, it facilitates autonomic nerve-preserving pelvic dissection with maintenance of adequate bladder and sexual function in the majority of the patients [63]. Considering this, it is conceivable that ligation of the IMA at its origin from the aorta will remain the preferred option in laparoscopic colorectal surgery.

\section{Conclusions}

We believe that high ligation of the IMA can be performed safely and does not represent a source of increased morbidity in surgery for rectal and left colonic cancers. In a small number of cases it might even be associated with an improved outcome, even though such evidence is largely limited to retrospective studies. More important, IMA high tie leads to improved lymph node harvest, thus facilitating accurate tumour staging. By reducing the stage migration phenomenon, it predicts the outcome more accurately, reliably identifies cases for adjuvant chemotherapy, and allows a standardized comparison of surgery-derived outcomes for individual units and surgeons.

The technique of high ligation of the IMA and IMV is simple, facilitates complete mobilization of the left colon and fashioning of a tension-free anastomosis, ensures complete excision of the entire lymph-node-bearing mesocolon, and prevents potential intravascular dissemination of cancer cells during tumour manipulation [58, 64].

Considering the above, it is conceivable that high tie of the IMA is finally coming off age a century after it was first advocated. Nevertheless, the need for a rigorous prospective randomized trial comparing high and low IMA ligation remains more imperative than ever.

\section{References}

1 IARC GLOBOCAN 2002: Cancer Incidence, Mortality and Prevalence Worldwide. wwwdep.iarc.fr/.

2 Toms JR (ed): Cancer Stats Monograph 2004. London, Cancer Research UK, 2004.

$\checkmark 3$ Nelson H, Petrelli N, Carlin A, Couture J, Fleshman J, Guilllem J, Miedema B, Ota D, Sargent D; National Cancer Institute Expert Panel: Guidelines 2000 for colon and rectal cancer surgery. J Natl Cancer Inst 2001;93: 583-596.

4 Kendal WS: Lymph-node-based prognostics: limitations with individualized cancer treatment. Am J Clin Oncol 2006;29:298304.
5 Phillips RK, Hittinger R, Blesovsky L, Fry JS, Fielding LP: Large bowel cancer: surgical pathology and its relationship to survival. $\mathrm{Br} \mathrm{J}$ Surg 1984;71:604-610.

6 Jamieson JK, Dobson JF: The lymphatics of the colon with special reference to the operative treatment of the colon. Ann Surg 1909; 50:1077-1090.

7 Gabriel W, Dukes C, Bussey H: Lymphatic spread in cancer of the rectum. Br J Surg 1935;23:395-413.

8 Goligher HC: The adequacy of the marginal blood supply to the left colon after hight ligation of the inferior mesenteric artery during excision of the rectum. Br J Surg 1954;41: 351-353.
9 Griffiths JD: The surgical anatomy of the blood supply of the distal colon. Ann R Coll Surg Engl 1956;19:241-256.

10 Moynihan BG: The surgical treatment of cancer of the sigmoid flexure and rectum. Surg Gynecol Obstet 1908;6:463-466.

11 Ferguson LK, Boland JP, Thomen FJ: Anterior segmental resection for carcinoma of the upper rectum, rectosigmoid and sigmoid. Surgery 1962;52:741-746.

12 Dukes CE, Bussey HJ: The spread of rectal cancer and its effect on prognosis. Br J Surg 1958;12:309-320. 
$\checkmark 13$ Rouffet F, Hay JM, Vacher B, Fingerhut A, Elhadad A, Flamant Y, Mathon C, Gainant A: Curative resection for left colonic carcinoma: hemicolectomy vs. segmental colectomy: a prospective, controlled, multicenter trial. Dis Colon Rectum 1994;37:651-659.

14 Rosi PA, Cahill WJ, Carey J: A ten year study of hemicolectomy in the treatment of carcinoma of the left half of the colon. Surg Gynecol Obstet 1962;114:14-24.

15 Grinnell RS: Results of ligation of inferior mesenteric artery at the aorta in resections of carcinoma of the descending and sigmoid colon and rectum. Surg Gynecol Obstet 1965;120:1031-1036.

16 Mallasagne B, Valleur P, Serra J, Sarnacki S, Galian A, Hoang C, Hautefeuille P: Relationship of apical node involvement to survival in resected colon carcinoma. Dis Colon Rectum 1993;36:645-653.

17 Pezim ME, Nicholls RJ: Survival after high or low ligation of the inferior mesenteric artery during curative surgery for rectal cancer. Ann Surg 1984;200:729-733.

- 18 Surtees P, Ritchie JK, Phillips RK: High versus low ligation of the inferior mesenteric artery in rectal cancer. Br J Surg 1990;77:618621.

19 Feinstein AR, Sosin DM, Wells CK: The Will Rogers phenomenon. Stage migration and new diagnostic techniques as a source of misleading statistics for survival in cancer. $\mathrm{N}$ Engl J Med 1985;312:1604-1608.

-20 Assmann SF, Pocock SJ, Enos LE, Kasten LE: Subgroup analysis and other (mis)uses of baseline data in clinical trials. Lancet 2000; 355:1064-1069.

-21 Slanetz CA Jr, Grimson R: Effect of high and intermediate ligation on survival and recurrence rates following curative resection of colorectal cancer. Dis Colon Rectum 1997; 40:1205-1218.

22 Grinnell RS: Quoted by Slanetz CA Jr, Herter FP; in: The Lymphatics in Cancer. Philadelphia, Saunders, 1972, pp 530-531.

-23 Adachi Y, Inomata M, Miyazaki N, Sato K, Shiraishi N, Kitano S: Distribution of lymph node metastases and level of inferior mesenteric artery ligation in colorectal cancer. J Clin Gastroenterol 1998;26:179-182.

-24 Steup WH, Moriya Y, van de Velde CJ: Patterns of lymphatic spread in rectal cancer. A topographical analysis on lymph node metastases. Eur J Cancer 2002;38:911-918.

-25 Kawamura YJ, Umetani N, Sunami E, Watanabe T, Masaki T, Muto T: Effect of high ligation on the long-term result of patients with operable colon cancer, particularly those with limited nodal involvement. Eur J Surg 2000;166:803-807.

-26 Ault GW, Castro AF, Smith RS: Carcinoma of upper rectum and rectosigmoid: clinical report on high inferior mesenteric ligation. Postgrad Med 1950;8:176-183.
7 Ault GW, Castro AF, Smith RS: Clinical study of ligation of inferior mesenteric artery in left colon resections. Surg Gynecol Obstet 1952;94:223-228.

28 Ault GW: A technique for cancer isolation and extended dissection for cancer of the distal colon and rectum. Surg Gynecol Obst 1958;106:467-477.

29 Bacon EH, McGregor JK: Prevention of recurrent carcinoma of the colon and rectum: report on 236 patients. Dis Colon Rectum 1963;6:209-214.

30 Harvey HD, Auchincloss H: Metastases to lymph nodes from carcinomas that were arrested. Cancer 1968;21:684-691.

31 McElwain JW, Bacon HE, Trimpi HD: Lymph node metastases: experience with aortic ligation of inferior mesentery artery in cancer of the rectum. Surgery 1954;35:513531.

32 Bacon HE, Dirbas F, Myers TB, Ponce De Leon F: Extensive lymphadenectomy and high ligation of the inferior mesenteric artery for carcinoma of the left colon and rectum. Dis Colon Rectum 1958;1:457-464.

33 Koyama Y, Moriya Y, Hojo K: Effects of extended systematic lymphadenectomy for adenocarcinoma of the rectum - significant improvement of survival rate and decreased local recurrence. Jpn J Clin Oncol 1984;14: 623-632.

34 Cecil TD, Sexton R, Moran BJ, Heald RJ: Total mesorectal excision results in low local recurrence rates in lymph node-positive rectal cancer. Dis Colon Rectum 2004;47:11451150.

35 Leggeri A, Roseano M, Balani A, Turoldo A: Lumboaortic and iliac lymphadenectomy: what is the role today? Dis Colon Rectum 1994;37(2 suppl):S54-S61.

36 Cosimelli M, Mannella E, Giannarelli D, Casaldi V, Wappner G, Cavaliere F, Consolo S, Appetecchia M, Cavaliere R: Nerve-sparing surgery in 302 resectable rectosigmoid cancer patients: genitourinary morbidity and 10-year survival. Dis Colon Rectum 1994;37(2 suppl):S42-S46.

37 Heald RJ: Total mesorectal excision is optimal surgery for rectal cancer: a Scandinavian consensus. Br J Surg 1995;82:12971299.

38 Kim NK, Aahn TW, Park JK, Lee KY, Lee WH, Sohn SK, Min JS: Assessment of sexual and voiding function after total mesorectal excision with pelvic autonomic nerve preservation in males with rectal cancer. Dis Colon Rectum 2002;45:1178-1185.

39 Hida J, Yasutomi M, Maruyama T, Fujimoto K, Nakajima A, Uchida T, Wakano T, Tokoro T, Kubo R, Shindo K: Indications for using high ligation of the inferior mesenteric artery in rectal cancer surgery. Dis Colon Rectum 1998;41:984-991.
40 Hida J, Mori N, Kubo R, Matsuda T, Morikawa E, Kitaoka M, Sindoh K, Yasutomi M: Metastases from carcinoma of the colon and rectum detected in small lymph nodes by the clearing method. J Am Coll Surg 1994;178: 223-228.

41 Hida J, Okuno K, Yasutomi M, Yoshifuji T, Matsuzaki T, Uchida T, Ishimaru E, Tokoro T, Shiozaki H: Optimal level of the primary feeding artery and bowel resection margin in colon cancer surgery: the influence of the site of the primary feeding artery. Dis Colon Rectum 2005;48:2232-2237.

42 Kawamura YJ, Sakuragi M, Togashi K, Okada M, Nagai H, Konishi F: Distribution of lymph node metastasis in T1 sigmoid colon carcinoma: should we ligate the inferior mesenteric artery? Scand J Gastroenterol 2005;40:858-861

43 Gollub MJ, Schwartz LH, Akhurst T: Update on colorectal cancer imaging. Radiol Clin North Am 2007;45:85-118.

44 Wald C, Scheirey CD, Tran TM, Erbay N: An update on imaging of colorectal cancer. Surg Clin North Am 2006;86:819-847.

45 Read TE, Mutch MG, Chang BW, McNevin MS, Fleshman JW, Birnbaum EH, Fry RD, Caushaj PF, Kodner IJ: Locoregional recurrence and survival after curative resection of adenocarcinoma of the colon. J Am Coll Surg 2002;195:33-40.

46 Kanemitsu Y, Hirai T, Komori K, Kato T: Survival benefit of high ligation of the inferior mesenteric artery in sigmoid colon or rectal cancer surgery. Br J Surg 2006;93:609615.

47 Hohenberger P, Schlag P, Kretzschmar U, Herfarth $\mathrm{CH}$ : Regional mesenteric recurrence of colorectal cancer after anterior resection or left hemicolectomy: inadequate primary resection demonstrated by angiography of the remaining arterial supply. Int J Colorectal Dis 1991;6:17-23.

48 Seike K, Koda K, Saito N, Oda K, Kosugi C, Shimizu K, Miyazaki M: Laser Doppler assessment of the influence of division at the root of the inferior mesenteric artery on anastomotic blood flow in rectosigmoid cancer surgery. Int J Colorectal Dis 2007;22: 689-697.

49 Hall NR, Finan PJ, Stephenson BM, Lowndes RH, Young HL: High tie of the inferior mesenteric artery in distal colorectal resections - a safe vascular procedure. Int J Colorectal Dis 1995;10:29-32.

50 Morgan CN, Griffiths JD: High ligation of the inferior mesenteric artery during operations for carcinoma of the distal colon and rectum. Surg Gynecol Obstet 1959;108:641650 .

51 Zhang C, Li GX, Ding ZH, Wu T, Zhong SZ: Preservation of the autonomic nerve in rectal cancer surgery: anatomical factors in ligation of the inferior mesenteric artery (in Chinese). Nan Fang Yi Ke Da Xue Xue Bao 2006;26:49-52. 
52 Nano M, Dal Corso H, Ferronato M, Solej M, Hornung JP, Dei Poli M: Ligation of the inferior mesenteric artery in the surgery of rectal cancer: anatomical considerations. Dig Surg 2004;21:123-126.

53 Hida J, Yasutomi M, Maruyama T, Uchida T, Nakajima A, Wakano T, Tokoro T, Kubo R: High ligation of the inferior mesenteric artery with hypogastric nerve preservation in rectal cancer surgery. Surg Today 1999;29: 482-483.

-54 Kim JC, Lee KH, Yu CS, Kim HC, Kim JR, Chang HM, Kim JH, Kim JS, Kim TW: The clinicopathological significance of inferior mesentericlymph node metastasis in colorectal cancer. Eur J Surg Oncol 2004;30:271279.

55 Hida I, Yasutomi M, Maruyama T, Fujimoto K, Uchida T, Okuno K: The extent of lymph node dissection for colon carcinoma. The potential impact on laparoscopic surgery. Cancer 1997;80:188-192.
Elsaleh H, Cserni G, Iacopetta B: Extent of nodal involvement in stage III colorectal carcinoma: relationship to clinicopathological variables and genetic alterations. Dis Colon Rectum 2002;45:1218-1222.

57 Newland RC, Chapuis PH, Smyth EJ: The prognostic value of substaging colorectal carcinoma. A prospective study of 1,117 cases with standardized pathology. Cancer 1987;60:852-857.

58 Köckerling F, Gastinger I, Schneider B, Krause W, Gall FP: Laparoscopic abdominoperineal excision of the rectum with high ligation of the inferior mesenteric artery in the management of rectal carcinoma. Endosc Surg Allied Technol 1993;1:16-19.

59 Delaney CP, Neary PC, Heriot AG, Senagore AJ: Operative procedures: low anterior resection and abdominoperineal resection; in Brown B, Seto J (eds): Operative Techniques in Laparoscopic Colorectal Surgery. Philadelphia, Lippincott Williams \& Wilkins, 2007, pp 81-94.

60 Breukink S, Pierie J, Wiggers T: Laparoscopic versus total mesorectal excision for rectal cancer. Cochrane Database Syst Rev 2006; 18:CD005200
1 Guillou PJ, Quirke P, Thorpe H, Walker J, Jayne DG, Smith AM, Heath RM, Brown JM; MRC CLASICC trial group: Short-term endpoints of conventional versus laparoscopicassisted surgery in patients with colorectal cancer (MRC CLASICC trial): multicentre, randomised controlled trial. Lancet 2005; 365:1718-1726.

62 Scheidbach H, Schneider C, Konradt J, Barlehner E, Kohler L, Wittekind CH, Köckerling F: Laparoscopic abdominoperineal resection and anterior resection with curative intent for carcinoma of the rectum. Surg Endosc 2002;16:7-13.

63 Liang JT, Lai HS, Lee PH: Laparoscopic pelvic autonomic nerve-preserving surgery for patients with lower rectal cancer after chemoradiation therapy. Ann Surg Oncol 2007; 14:1285-1287.

64 Abcarian H, Pearl RK: Simple technique for high ligation of the inferior mesenteric artery and vein. Dis Colon Rectum 1991;34: 1138 . 